\title{
Prioritization of water management under climate change and urbanization using multi-criteria decision making methods
}

\author{
J.-S. Yang ${ }^{1}$, E.-S. Chung ${ }^{2}$, S.-U. Kim ${ }^{3}$, and T.-W. Kim ${ }^{4}$ \\ ${ }^{1}$ School of Civil and Environmental Engineering, Kookmin University, 136-702 Seoul, Republic of Korea \\ ${ }^{2}$ School of Civil Engineering, Seoul National University of Science and Technology, Gongneung-Ro 232, Nowon-gu, \\ 139-743 Seoul, Republic of Korea \\ ${ }^{3}$ Department of Civil Engineering, Kangwon National University, 200-701 Kangwon, Republic of Korea \\ ${ }^{4}$ Water Resources Department, Websolus Co., 152-848 Seoul, Republic of Korea
}

Correspondence to: E.-S. Chung (eschung@ seoultech.ac.kr)

Received: 11 September 2011 - Published in Hydrol. Earth Syst. Sci. Discuss.: 10 November 2011

Revised: 26 February 2012 - Accepted: 28 February 2012 - Published: 12 March 2012

\begin{abstract}
This paper quantifies the transformed effectiveness of alternatives for watershed management caused by climate change and urbanization and prioritizes five options using multi-criteria decision making techniques. The climate change scenarios (A1B and A2) were obtained by using a statistical downscaling model (SDSM), and the urbanization scenario by surveying the existing urban planning. The flow and biochemical oxygen demand (BOD) concentration duration curves were derived, and the numbers of days required to satisfy the environmental flow requirement and the target BOD concentration were counted using the Hydrological Simulation Program-Fortran (HSPF) model. In addition, five feasible alternatives were prioritized by using multi-criteria decision making techniques, based on the driving force-pressure-state-impact-response (DPSIR) framework and cost component. Finally, a sensitivity analysis approach for MCDM methods was conducted to reduce the uncertainty of weights. The result indicates that the most sensitive decision criterion is cost, followed by criteria response, driving force, impact, state and pressure in that order. As it is certain that the importance of cost component is over 0.127 , construction of a small wastewater treatment plant will be the most preferred alternative in this application.
\end{abstract}

\section{Introduction}

Both urbanization, primarily through the construction of impervious cover, and climate change, mainly through extensive increase of temperature and severe variation of precipitation, progressively impact the hydrologic, physical, and biological qualities of aquatic health. That is, urbanization increases annual storm water runoff, diminishes baseflow, degrades stream habitat conditions, deteriorates water quality, and reduces the diversity of aquatic insects, riparian plants, and fish (CWP, 2005). In case of climate change, the resulting impacts on instream flow, BOD concentration, and ecological status of relevant ecosystems varies in different localities.

Therefore, an increasing consensus supports that climate change and urbanization should be considered in making water resources and environmental management decisions. Clearly, many of the decisions made in the past have either had only short-term consequences or have only been weakly climate sensitive. Yet, the majority of the environment management decisions come with long-term commitments, and they are often very sensitive to climate and land use. Examples of such decisions can be risk management strategies, infrastructure development for water management. These decisions such as flood mitigation plans have consequences over periods of 50-200 years. These kinds of decisions are also vulnerable to changes in climate and land use conditions and also to rising sea levels (Hallegatte, 2009).

Some studies on climate change have focused on the issue of robust decisions; however, most of them have mainly focused on the mitigation side of the problem (Lempert et al., 1996; van Lenthe et al., 1997; Lempert and Schlesinger, 2000; Caldeira et al., 2003; Yohe et al., 2004). Even less researched is the identification of robust decisions about uncertainties of climate change projections in the context of adaptation, mainly because of the lack of consistent treatment of uncertainties in climate change scenario constructions (Carter et al., 2001). Some attempts have been made to examine robust adaptation decisions against climate change

Published by Copernicus Publications on behalf of the European Geosciences Union. 
uncertainties (Yohe, 1996; Hobbs, 1997; Hobbs et al., 1997; Risbey, 1998); however, they only sampled a fraction of the known range of future climates.

Much attention has been paid to climate change impacts and the relevant policy responses, such as a goalprogramming approach to regional policy responses (Yin and Cohen, 1994), a multi-objective programming method for land resources adaptation planning (Huang et al., 1998), a statistical approach to identifying policy areas (Smith, 1997), an integrated approach based on the analytic hierarchy process (AHP) for evaluating adaptation options of water resources (Yin, 2001), a multi-criteria decision-making-based expert system for climate change impact assessment and adaptation planning (Qin et al., 2008), and an analysis of water management options and climate change scenarios (Sulis et al., 2009). Many studies have also investigated on the impacts of land use changes and the relevant policy responses (Bae et al., 2007; Lee and Chung, 2007a; Praskievicz and Chang, 2007; Chung et al., 2011c).

Generally, adaptation to climate change and urbanization is inadequate, and most existing watershed management plans have not considered their impacts. For instance, options for sustainable water resources management and planning should include the potential effects of climate change and urbanization on the hydrological cycle. However, few studies have dealt with the impacts of either climate change or urbanization and relevant policies. Therefore, we have conducted an effectiveness analysis on alternatives for watershed management by considering urbanization and climate change scenarios. The climate change scenarios were obtained using a statistical downscaling model (SDSM; Wilby et al., 2002), and the anticipated urbanization scenarios from the existing urban planning.

Watershed management and planning for climate change adaptation and mitigation is closely related to the multicriteria decision making (MCDM) problem. There have been many studies on water resources planning and management using various MCDM methods (Pavlikakis and Tsihrintzis, 2003; Chen and Hou, 2004; Levy et al., 2007; Meyer et al., 2009; Chung and Lee, 2009; Al-Juaidi et al., 2010; Zardari et al., 2010; Chung et al., 2011a). In decision making, the weights assigned to the decision criteria attempt to represent the genuine importance of the criteria. When criteria cannot be expressed in quantitative terms, then it is difficult to represent the importance of these criteria accurately. In a situation like the above, the decision making process could be improved considerably by identifying the critical criteria and then re-evaluating the weights of these criteria more accurately. The intuitive belief is that the criterion with the highest weight is the most critical one. This may not always be true and in some instances the criterion with the lowest may be most critical.

The decision maker can make better decisions if one can determine how critical each criterion is. That is, how sensitive the actual ranking of the alternatives is to changes in the current weights of the decision criteria. Therefore, this study determined how critical each criterion is, by performing a sensitivity analysis on the weights of the criteria. This sensitivity analysis approach determines the smallest change in the current weights of the criteria, which can alter the existing ranking of the alternatives (Triantaphyllou, 2000).

This study consists of two analyses. Firstly, the effectiveness analyses of watershed managements were conducted using the Hydrological Simulation Program in Fortran (HSPF; Bicknell et al., 2001), to examine the climate change and urbanization scenarios. Applying the methodology and results of Chung et al. (2011c), the flow and biochemical oxygen demand (BOD) concentration duration curves were derived, and the numbers of days required to satisfy the environmental instream flow needs (EIF) and target BOD concentration were counted. Secondly, the prioritization of water management was determined using Multi-Criteria Decision Making (MCDM) techniques. The driving force-Pressure-StateImpact-Response (DPSIR; European Environmental Agency, 1999) framework and cost component were used to consider all relevant indicators including social, economic and environmental factors. Finally, a sensitivity analysis of the MCDM methods was conducted to reduce the uncertainty of weighting values.

\section{Description of the selected watershed}

The Suamcheon (SA), Ojeoncheon (OJ) and Dorimcheon (DR) streams are branches of the Anyangcheon which is the first-order tributary of the Han River (Fig. 1). This study selected three sub-watersheds because the Anyangcheon watershed located in the central Korea near Seoul, has been observed to have serious problems in the quantity as well as the quality of water. The length of the Anyangcheon River is $32.38 \mathrm{~km}$; it drains the watershed area of $287 \mathrm{~km}^{2}$ that contains 3.88 million people (population density of $\sim 13500$ persons $\mathrm{km}^{-2}$ ). The watershed land cover consists of $43 \%$ urban area, $40 \%$ forest, and $13 \%$ agricultural fields (as of 2000). The water supply systems in the study watershed are mainly surface water (approximately over $98 \%$ ). But private groundwater supply systems have been used, occasionally. The amount cannot be measured because it is illegal (Lee et al., 2008).

This study was applied to the Anyangcheon watershed which has suffered from potential streamflow depletion and possible water quality deterioration (Chung and Lee, 2009b). Therefore, some local governments had strong political wills to restore the distorted hydrological cycle through some suggested measures as follows: redevelopment of the existing reservoir, reuse of treated waste water effluent, use of groundwater poured into subway stations and construction of a small waste water treatment plant (WWTP). Four kinds of alternatives are intended to secure the abundant instream flow and induce water quality enhancement. 


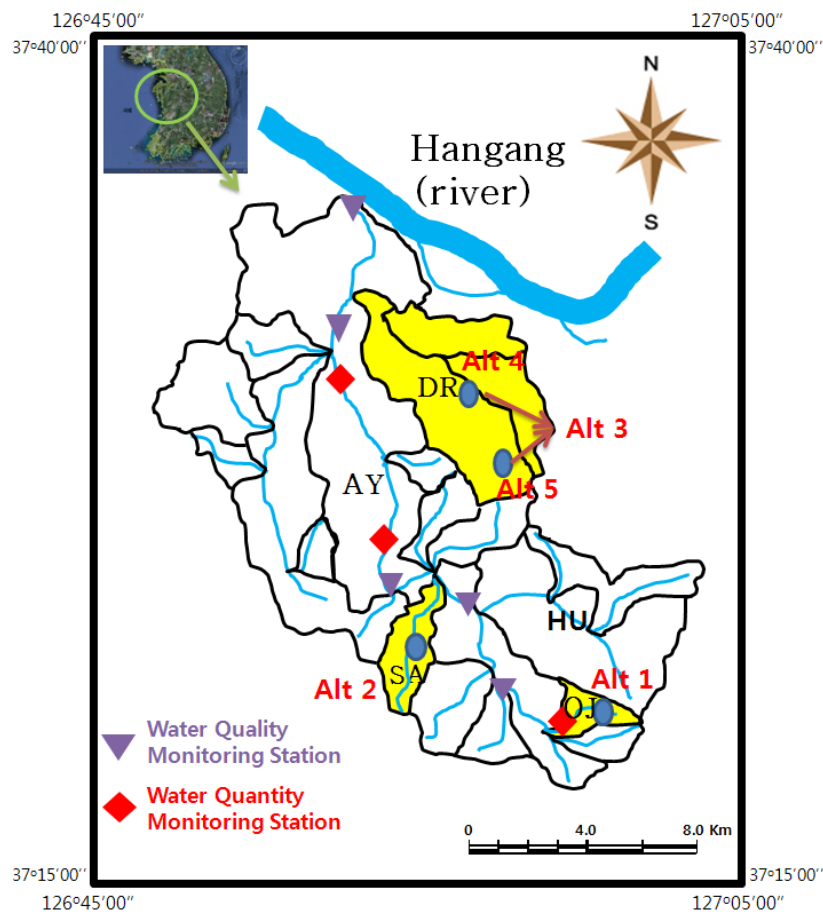

Fig. 1. Map of the study watershed.

The channel lengths of the OJ, SA and DR are $2.85 \mathrm{~km}$, $5.50 \mathrm{~km}$, and $14.20 \mathrm{~km}$ and the areas of OJ, SA, and DR watershed are $4.26 \mathrm{~km}^{2}, 8.07 \mathrm{~km}^{2}$, and $40.96 \mathrm{~km}^{2}$, respectively. $\mathrm{OJ}$ is located in the upstream region of the Anyangcheon, SA in the middle-stream, and DR in the downstream region as shown in Fig. 1. The urban area ratios in 2000 were $11.4 \%, 25.4 \%$, and $62.3 \%$, respectively. The populations were 26370 for OJ, 49960 for SA and 982804 for DR.

Chung and Lee (2009a) showed that approximately $40.5 \%$ (OJ), $43.5 \%$ (SA) and $70.3 \%$ (DR) of the precipitation input to the study watersheds is discharged as direct runoff, and approximately $11.3 \%(\mathrm{OJ}), 9.4 \%(\mathrm{SA})$, and $1.8 \%(\mathrm{DR})$ of the precipitation is discharged as baseflow. That is, since base flows of three watersheds are very small, it can be easily guessed that the instream flow would not be enough. Especially, DR shows the depleted stream during all dry periods (October $\sim$ April).

Also, modeling studies were conducted to analyze the BOD concentration, which has estimated to be approximately $13.3 \mathrm{mgl}^{-1}(\mathrm{OJ}), 10.1 \mathrm{mgl}^{-1}$ (SA), and $20.5 \mathrm{mgl}^{-1}$ (DR) and the daily load to be $68.9 \mathrm{~kg} \mathrm{day}^{-1}$ (59.0 $\mathrm{kg} \mathrm{ha}^{-1} \mathrm{yr}^{-1}$, OJ), $68.4 \mathrm{~kg} \mathrm{day}^{-1}\left(30.9 \mathrm{~kg} \mathrm{ha}^{-1} \mathrm{yr}^{-1}\right.$, $\mathrm{SA}$ ), and $292.8 \mathrm{~kg} \mathrm{day}^{-1}\left(25.7 \mathrm{~kg} \mathrm{ha}^{-1} \mathrm{yr}^{-1}\right.$, DR) (Chung and Lee, 2009). That is, since average BOD concentration of three study watershed are too high (over $10 \mathrm{mgl}^{-1}$ ), it is definitely necessary to develop some measures for the reduction of BOD concentration. As a result, fish of the study watershed have died frequently from even small rainfall events. From this result, this study determined the target pollutant as BOD since the study watershed has suffered from BOD concentration problems for a long time.

Chung et al. (2011c) showed that the temperatures of the Anyangcheon watershed (1964-2008) have a strong increasing trend using the Mann-Kendall trend test. In addition, the water supply structure in the study watersheds consists of mainly surface water and rarely private groundwater supply systems.

\section{Methodology}

\subsection{Procedure}

This study is carried out in five stages as shown in Fig. 2. At Step one, five alternatives for three watersheds were proposed from Chung and Lee (2009a). The alternatives are (Alt 1) redevelopment of the existing reservoir, (Alt 2) reuse of highly-treated WWTP effluent, (Alt 4) construction of small WWTP, (Alt 5) use of groundwater collected by subway stations and (Alt 3) combination of Alt 4 and 5.

At Step two, future climate change scenarios and planned urbanization scenario were developed. First, the Coupled Global Climate Model 3 (CGCM3), a popular global circulation model, was selected. Since this study focus on the development of decision making procedure considering climate change and urbanization, just one GCM result was used. A1B and A2 from CGCM3 were chosen from the Special Report Emission Scenarios (SRES) based on realistic feasibility. All precipitation and temperature data under this study were downscaled through the statistical downscaling model, SDSM-a software package accompanying statistical downscaling methodology that enables construction of climate change scenarios for individual sites at daily timescales, using the grid resolution GCM output. For the urbanization scenarios, the land use change scenarios of the selected watersheds were individually constructed from the existing urban planning 2020.

Step three is to quantitatively analyze the effectiveness of all the alternatives by all the climate change and urbanization scenarios using the HSPF model. HSPF can simulate the hydrologic and associated water quality processes on pervious and impervious land surface and in streams and well-mixed impoundments. The duration curves of flow and BOD concentration of all the sub-watersheds were identified and the numbers of days required to satisfy the target instream flow and BOD concentration were counted. The instream flow is the amount of water needed in a stream to adequately provide for downstream uses occurring within the stream channel and the target BOD concentration is the daily ave. determined by local governments. This study watershed covers some or all of the following uses that extend beyond the need for aquatic habitat, recreation, riparian vegetation and water quality. The target instream flow and BOD concentration for all sub-watersheds were collected from Lee and 


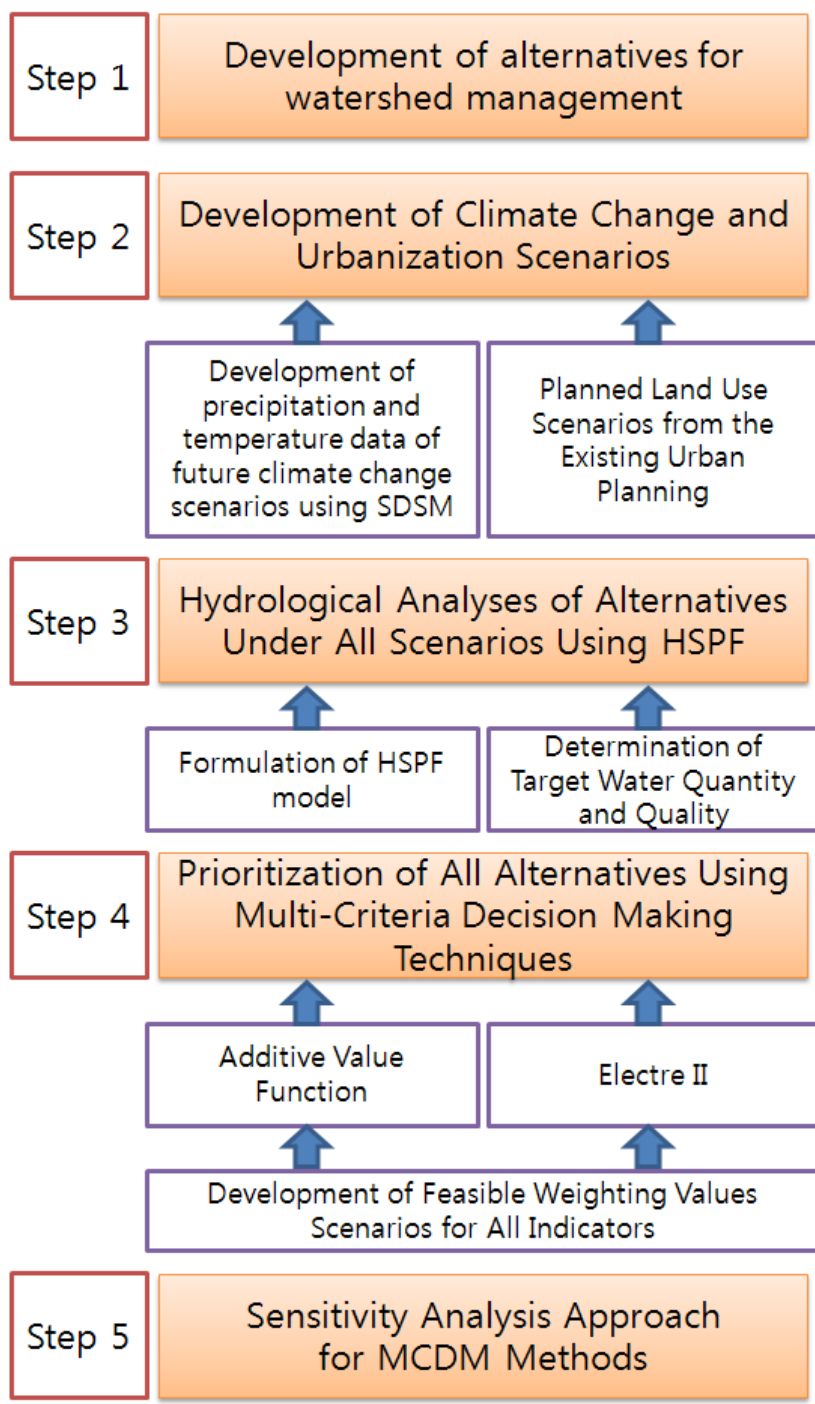

Fig. 2. Procedure of this study.

Chung (2007b) and Chung et al. (2011b); they were calculated by considering the stream flow seasonal variability and the fish habitat suitability at this step.

Step four is to prioritize five alternatives reflecting the future climate change and urbanization. Multi-criteria decision making techniques include a simple additive weighting method and ELECTRE II (Elimination and Choice Translating Reality). For the rational consideration of social and economic factors, all criteria were selected from the DPSIR framework which uses a cause-effect relationship. Since the weighting values evaluation is a time-consuming process, this study developed some feasible scenarios for weighting values.

The final step is to do a sensitivity analysis of MCDM methods. In this application, this study determined how critical each criterion is by performing a sensitivity analysis on the weights of the criteria.

\subsection{Hydrologic model}

This study modified Chung et al.'s (2011c) HSPF model to estimate flow rate and BOD loads in the Anyangcheon watershed. HSPF requires physical (topographic and land use) and climate data and stream flow and water quality data are required for calibration and validation. Therefore, a 1:25000 digital elevation model (DEM) and landuse map of the year 2000 of the study watershed were used as physical data. Also, climate data (daily precipitation, temperature, ave. wind speed, ave. humidity, and ave. solar radiation data) of Suwon and Seoul weather stations operated by Korean Meteorological Administration (KMA) were introduced to the climate data input of HSPF since the study watershed is located between two stations. Stream water quantity and quality data were obtained from Lee (2007) and Ministry of Environment of Korea. This study used the validated HSPF model of Chung et al. (2011c) that presents the results of the sensitivity analysis and results of calibration and validation. In case of flow rate, Nash-Sutcliffe coefficients showed $0.67 \sim 0.81$ for calibration and $0.62 \sim 0.72$ for verification and in case of BOD concentration, RMSE showed $1.61 \sim 4.43 \mathrm{mg} \mathrm{l}^{-1}$ for calibration and $1.95 \sim 15.18 \mathrm{mg} \mathrm{l}^{-1}$ for verification.

\subsection{Downscaling method}

The daily mean temperature and precipitation are calculated for the study watershed using CGCM3 model output from A1B and A2 emission scenarios for the future senarios (2011-2100) and SDSM. Chung et al. (2011c) showed the procedure and results for calibration and verification. From the Mann-Kendall test (2010-2100), it can be estimated that Seoul and Suwon weather stations have a strong tendency for increasing temperatures and precipitation as shown in Fig. 3.

The ave. temperature at Seoul and Suwon stations would increase by $1.6^{\circ}$ and $2.0^{\circ}$ under $\mathrm{A} 1 \mathrm{~B}$ and $2.0^{\circ}$ and $2.4^{\circ}$ under A2 during the period 2010-2100, respectively. Especially, the summer temperature of Seoul (A2) would increase up to $4.2^{\circ}$. The ave. precipitation at Seoul and Suwon stations are $1896.9 \mathrm{~mm}$ and $1679.5 \mathrm{~mm}$ under A1B and $2029.5 \mathrm{~mm}$ and $1803.6 \mathrm{~mm}$ under A2. Especially, the summer intensity of Seoul station increased severely from $845.9 \mathrm{~mm}$ to $1317.3 \mathrm{~mm}$ (A2) and the remaining seasons didn't show any extreme increases.

\subsection{DPSIR framework}

DPSIR stands for Driving force-Pressure-State-ImpactResponse; the components of an analytical framework that links the socioeconomic factors (driving force) forcing anthropogenic activities (pressure), the resulting environmental conditions (state), the environmental consequences resulting from these conditions (impact) and finally, the 

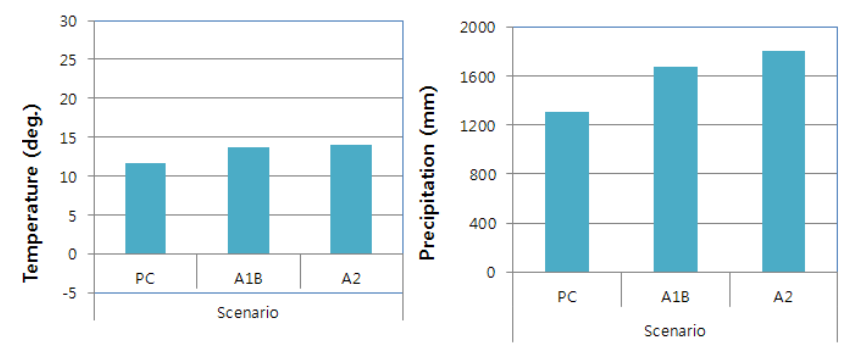

Fig. 3. Summary of forecasted temperature and precipitation results.

measures taken to improve the environmental state (response) (Skoulikidis, 2009).

\subsection{Additive Value Function (AVF)}

The AVF method is a simplified version of a multi-attribute utility function (MAUF). In MAUF method, the risk attitude of the decision-maker can be incorporated through a concave (risk averse) or a convex (risk seeker) utility curve. The way scores are normalized in the AVF method makes it an MAUF method for a decision-maker that has a risk-neutral or riskadverse attitude (Clemen, 1997). Each score $\left(s_{i j}\right)$ in the matrix is replaced with a value $v_{i j}$ according to Eq. (1):

$v_{i j}=\frac{s_{i j}-s_{i-}}{s_{i+}-s_{i-}}$

where $s_{i j}$ is the impact of an scenario $(j)$ with respect to a criterion $(i) ; s_{i-}$ is the worst score of the criterion $(i)$ with respect to all scenarios; and $s_{i+}$ is the "best" score of the criterion $(i)$ with respect to all scenarios. All scores in the payoff matrix are scaled between the values of 0.0 and 1.0. An overall value index $\left(V_{j}\right)$ for each scenario is calculated as shown in Eq. (2):

$V_{j}=\sum_{i=1}^{n} w_{i} v_{i j}$

where $w_{i}$ is the relative weight assigned to criterion $(i)$ and $n$ is the total number of criteria.

This study used the concept of payoff matrix which consisted of rows and columns. Each row represents one action that the decision maker might or might not freely choose to perform and each column represents a possible state of nature. At the time the decision must be made the decision maker assumes that one of the columns represents the actual decision situation, but the decision maker does not know which column is the correct one. The cell of the matrix represent payoffs that the decision maker would receive if the decision maker chose the action represented by a particular row and the actual state of nature were the one represented by a particular columns.

\subsection{ELECTRE II}

ELECTRE II is an improved version of ELECTRE family that produces a ranking of alternatives rather than indicating the most preferred. It outranks based on alternatives that are preferred with respect to most of the criteria and that do not drastically fail with respect to any one or more criteria. The first attribute is expressed by the "concordance" index and the second by the "discordance" index. Alternative A outranks Alternative $\mathrm{B}$ if both concordance and discordance indices are satisfied. The concordance index $C(A, B)$ measures the strength of support in the information given for the hypothesis that $A$ is at least as good as $B$. The discordance index $D(A, B)$ measures the strength of evidence against this hypothesis. $C(A, B)$ can be calculated as shown in Eq. (3).

$C(A, B)=\frac{w^{+}+w^{=}}{w^{+}+w^{=}+w^{-}}$

where $w^{+}$is the sum of the weights of all criteria where $A$ is better than $B ; w^{-}$is the opposite case, i.e., the sum of the weights of the criteria where $B$ is better than $A$; and $w^{=}$is the indifferent cases. $D(A, B)$ can be calculated as shown in Eq. (4).

$D(A, B)=\max \left(v_{i B}-v_{i A}\right)$

where $v_{i B}$ is the value function of the impact of alternative $B$ with respect to criterion $(i)$ and $v_{i A}$ is the value function of the impact of alternative $A$ to outrank $B, C(A, B)$ has to be greater than $D(A, B)$, and both of $C(A, B)$ and $D(A, B)$ should be higher than a present threshold value $p$ and lower than a preset threshold value $q$, respectively. Moreover, $w^{+}$ has to be greater than $w^{-}$.

\subsection{Sensitivity analysis approach for MCDM methods}

There must be three assumptions for the sensitivity analysis to criteria of MCDM methods as follows (Triantaphyllou, 2000):

- Assumption 1:

Let $\delta_{k, i, j}$ (for $1 \leq i<j \leq m$ and $1 \leq k \leq n$ ) denote the minimum change in the current weight $w_{k}$ of criterion $c_{k}$ such that the ranking of alternatives $A_{i}$ and $A_{j}$ will be reversed. Next $\delta_{k, i, j}^{l}$ is defined as follows:

$$
\begin{gathered}
\delta_{k, i, j}^{l}=\delta_{k, i, j} \times \frac{100}{w_{k}} \text { for any } 1 \leq i<j \leq m \\
\text { and } 1 \leq k \leq n .
\end{gathered}
$$

That is, the parameter $\delta_{k, i, j}^{l}$ expresses changes in relative terms. 
- Assumption 2:

- The Percent-Top critical criterion is the criterion which corresponds to the smallest $\left|\delta_{k, 1, j}^{l}\right|$ (for $1 \leq j \leq m$ and $1 \leq k \leq n)$ value.

- The Percent-Any critical criterion is the criterion which corresponds to the smallest $\left|\delta_{k, i, j}^{l}\right|$ (for $1 \leq i<j \leq m$ and $1 \leq k \leq n)$ value.

- Assumption 3:

The criticality degree of criterion $c_{k}$ denotes as $D_{k}^{\prime}$ id the smallest percent amount by which the current value of $w_{k}$ must change, such that the existing ranking of the alternatives will change. That is, $D_{k}^{\prime}$ can be calculated as follows:

$D_{k}^{\prime}=\min _{1 \leq i<j \leq m}\left\{\left|\delta_{k, i, j}^{\prime l}\right|\right\}$, for all $n \geq k \geq 1$

The sensitivity coefficient of criterion $c_{k}$ denotes as $\operatorname{sens}\left(c_{k}\right)$, is the reciprocal of its criticality degree. That is, $\operatorname{sens}\left(c_{k}\right)$ can be calculated as follows:

$\operatorname{sens}\left(c_{k}\right)=\frac{1}{D_{k}^{\prime}}$, for all $n \geq k \geq 1$.

If the criticality degree is impossible to change any alternative rank with any weight change, then the coefficient is set to be equal to zero.

For this case, it is assumed that a decision maker used AVF and wishes to alter the existing ranking of the two alternatives $A_{i}$ and $A_{j}$ by modifying only the current weight $w_{k}$ of criterion $c_{k}$. If $P_{i} \geq P_{j}$, Triantaphyllou (2000) showed the minimum quantity $\delta_{k, i, j}$, needed to reverse the current ranking of the two alternatives $A_{i}$ and $A_{j}$, should satisfy the following relation:

$$
\begin{aligned}
\delta_{k, i, j} & <\frac{\left(P_{j}-P_{i}\right)}{\left(a_{k j}-a_{k i}\right)}, \text { if } a_{k i}>a_{k j}, \\
& \text { or } \delta_{k, i, j}>\frac{\left(P_{j}-P_{i}\right)}{\left(a_{k j}-a_{k i}\right)}, \text { if } a_{k i}<a_{k j} .
\end{aligned}
$$

Furthermore, Eq. (10) should also be satisfied for the new weight $w_{k}^{*}$ (Eq. 9) to be feasible:

$w_{k}^{*}=w_{k}-\delta_{k, i, j}$

$\begin{array}{ll}w_{k}^{*} & \geq 0 \quad \text { or } \\ w_{k}-\delta_{k, i, j} & \geq 0 \quad \text { or } \\ w_{k} & \geq \delta_{k, i, j}\end{array}$

At this step, $w_{i}^{*} \leq 1$ is not required.
The quantity, $\delta_{k, i, j}^{l}$, by which the current weight $w_{k}$ of criterion $c_{k}$ needs to be modified so that the ranking of the alternatives $A_{i}$ and $A_{j}$ will be reversed, must be satisfied as follows:

$$
\begin{aligned}
\delta_{k, i, j}^{l}< & \frac{\left(P_{j}-P_{i}\right)}{\left(a_{k j}-a_{k i}\right)} \times \frac{100}{w_{k}}, \text { if } a_{k i}>a_{k j}, \\
& \text { or } \delta_{k, i, j}^{l}>\frac{\left(P_{j}-P_{i}\right)}{\left(a_{k j}-a_{k i}\right)} \times \frac{100}{w_{k}}, \text { if } a_{k i}<a_{k j} .
\end{aligned}
$$

Furthermore, Eq. (12) should also be satisfied for the value of $\delta_{k, i, j}^{l}$ to be feasible:

$$
\frac{\left(P_{j}-P_{i}\right)}{\left(a_{k j}-a_{k i}\right)} \leq w_{k} \text {. }
$$

\section{Results}

\subsection{Alternatives for watershed management}

This study used the five alternatives for OJ, SA and DR that Chung and Lee (2009a) have developed for integrated watershed management. They are shown in Fig. 1 and their detailed descriptions are as follows:

- Alt $1(\mathrm{OJ})$ : redevelopment of the existing reservoir (capacity: $55000 \mathrm{~m}^{3}$, outflow: $\left.0.01 \mathrm{cms}\right)\left(A_{1}\right)$

- Alt 2 (SA): reuse of treated waste water effluent (discharge quantity: $11000 \mathrm{~m}^{3}$ day $^{-1}$ and discharge concentration: $4.7 \mathrm{mg} \mathrm{l}^{-1}$ of BOD) $\left(A_{2}\right)$

- Alt 3 (DR): use of the groundwater collected by subway $\left(17.703 \mathrm{~m}^{3}\right)$ and construction of a small WWTP (capacity: $12540 \mathrm{~m}^{3} \mathrm{day}^{-1}$ and discharge concentration: $5.0 \mathrm{mg} \mathrm{l}^{-1}$ of BOD) $\left(A_{3}\right)$

- Alt 4 (DR): use of groundwater collected by subway $\left(A_{4}\right)$

- Alt 5 (DR): construction of a small WWTP $\left(A_{5}\right)$.

The initials in all parentheses refer to the name of the watershed where each alternative is proposed to be set up.

The small reservoir in $\mathrm{OJ}$ was built for the agricultural uses about fifty years ago. Now, it, however, is not used anymore for that reason because the agricultural area has been substituted by the urban. Therefore, the reservoir should be redeveloped for the target instream flow (Alt 1). Recently, treated waste water effluents were reused for sustainable water management in Korea, frequently. The transfer system was constructed in SA and operated to supply plenty of instream flow and enhance water quality (Alt 2). Since the groundwater level in the study watershed is fluctuating all year around, groundwater gets into subway station occasionally. Most subway stations transferred the groundwater to 
the WWTP through sanitary sewers. However, the groundwater quantity is relatively enough and the quality is acceptable. Therefore, the groundwater getting into subway station should be transferred to the depleted streams in order to sustain the target instream flow and BOD concentration through the pumping device and transfer system. This would increase the numbers of days where the EIF is acceptable due to the increase of instream flow (Alt 4). A small WWTP was proposed about twenty years ago to maintain small water depth since DR stream had suffered from extremely depleted instream flow (Alt 5).

\subsection{Future scenarios for climate change and urbanization}

This study used the downscaled precipitation and temperature data from Chung et al. (2011c) which used CGCM3 to develop some future climate change scenarios (A1B and A2). The SDSM indicated (forecasted) that the annual ave. temperatures would increase by $1.8^{\circ} \mathrm{C} \sim 2.4^{\circ} \mathrm{C}$ under A1B and by $2.7^{\circ} \mathrm{C} \sim 4.3^{\circ} \mathrm{C}$ under $\mathrm{A} 2$ during the period $2010-2100$. The increased values were not biased to particular seasons. In addition, the annual ave. precipitations would increase by $90 \sim 440 \mathrm{~mm}$ under $\mathrm{A} 1 \mathrm{~B}$ and by $360 \sim 500 \mathrm{~mm}$ under $\mathrm{A} 2$, during the period $2010 \sim 2100$. The total rainfall during the summer increases and the amount of rainfall in the remaining months decreases. That is, the flood control and the water supply would become increasingly difficult (Chung et al., 2011c).

The Anyangcheon watershed has been urbanized rapidly over the past 40 years regardless of previous urban planning. The urban area ratio increased from $16.7 \%$ in 1975 to $43.2 \%$ in 2000. In addition, three studied watersheds OJ, SA, and DR have been urbanized from $2.5 \%$ to $11.4 \%$, and $4.5 \%$ to $25.4 \%$, and $25.7 \%$ to $60.3 \%$, respectively, over the last 25 years. The urban area ratio is still on the increase through political connections and economic demands.

The existing urban planning reports forecasted the future urban area ratios of OJ, SA, and DR individually to be as follows: OJ (25\%), SA (60\%), and DR (no increase in urbanization). When the impervious area was added to the watershed, new urban areas were developed adjacent to the existing city. Although new cities can be developed in the upstream region or without any consideration for the old cities, this study assumed homogeneity for urban growth.

\subsection{Hydrological analyses}

In this study, HSPF was formulated to simulate the flowrate and BOD loads of the Anyangcheon watershed, including OJ, SA and DR. Because the three study-watersheds (OJ, $\mathrm{SA}$, and DR) have no monitoring data, HSPF was constructed at the Anyangcheon watershed which includes OJ, SA, and DR. Therefore, this study used the HSPF model constructed by Chung et al. (2011b). It has shown the detailed HSPF

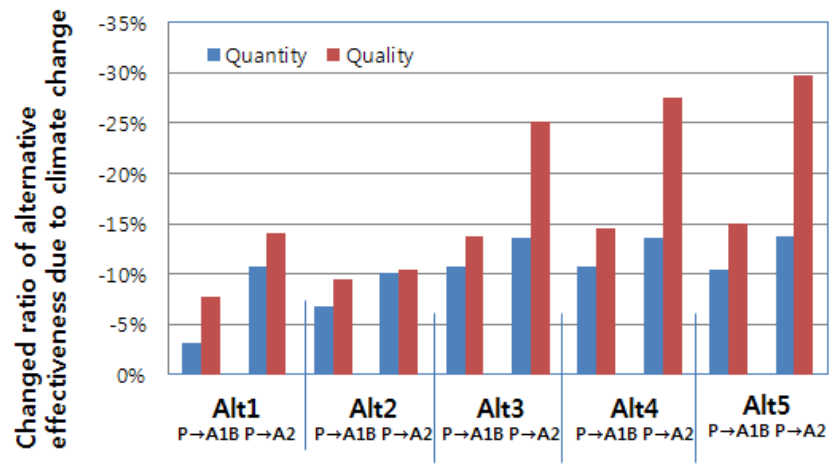

Fig. 4. Changed ratio of alternative effectiveness due to climate change.

formulation process and described the periods of performance, the model efficiencies, and the RMSEs that resulted from the calibration and validation.

The hydrological output was examined in terms of the flow and BOD concentration duration curves which is useful in quantifying the stream flow quantity and quality variability. This study adopted all the criteria from Hejazi and Moglen (2008), which are the 90, 95, and 99 percentile values for water quantity during the dry period. Three criteria were selected to assess the water quality, i.e. the 1,10 , and 30 percentile values of the daily ave. pollutant concentration.

It is probably true that the anticipated effectiveness of all the alternatives for watershed management, which was estimated at the design process, will be changed if climate change is not considered. Definitely, land use change would pose the same problem for water resources/watershed planning. Therefore, this study analyzed the differences of simulated results between water resources/watershed planning with and without climate change impacts. In these analyses, it is assumed that land use change will come up with climate change. So, climate change scenarios were projected to the planned land use scenarios. In other words, we compared two scenarios: one scenario for the present climate and land use conditions and the other scenario for the forecasted climate change and planned land use change conditions. The ratios of effectiveness changed to low flow (quantity) and ave. BOD concentration (quality) were analyzed as shown in Fig. 4.

As a result, the effectiveness of all the alternatives to water quantity and quality decreased, and A2 scenario showed more severe reduction than A1B. Alt 3 showed the largest reduction of water quantity effectiveness at A1B scenario, while Alt 5 at A2. On the other hand, Alt 5 was analyzed to show the largest reduction of water quality effectiveness at both A1B and A2 scenarios.

Since the watersheds proposed in Alt 1 and Alt 2 will be planned to be urbanized, the expected changes in the ratio of alternative effectiveness due to urbanization are calculated, and the results are shown in Fig. 5. In general, the changed effectiveness to quantity showed a much larger increase than 


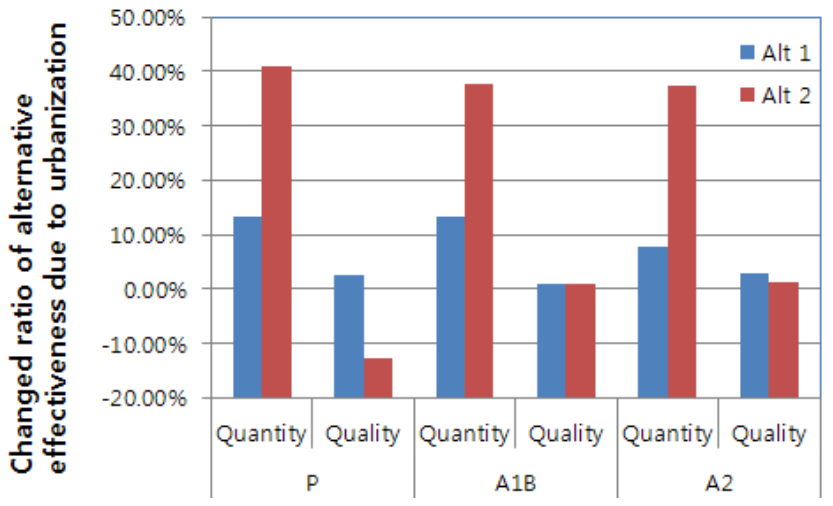

Fig. 5. Changed ratio of alternative effectiveness due to urbanization.

that to quality. In addition, the effectiveness will decrease because of climate change.

In the case of the numbers of days required to satisfy the target water quantity and quality, four alternatives among five showed that the effectiveness of both water quantity and quality decreased because of climate changes. On the other hand, the analysis of Alt 2 showed that the effectiveness of water quantity and quality is increased because of climate changes.

When compared to the OJ, and SA results, the combination of construction of small WWTP and use of groundwater collected by subway station showed high effectiveness but was more sensitive to climate change. The effectiveness of SA was by far the greater than that of OJ and DR. In addition, the alternative having large improvements of hydrological cycles shows a larger decrease in effectiveness due to climate change as shown in Figs. 4 and 5 and Table 1. Finally, the impacts of the present watershed management plans may change in the near future since the possibilities of urbanization and climate changes are increasing. The scale and capacity of the alternatives should be expanded considering the impacts of climate changes and urbanization.

\subsection{Prioritization of alternatives using multi-criteria decision making techniques}

New decision making for future water management should consider social and economic factors. Based on the DPSIR framework, as shown in Sect. 2.4, the criteria for alternative ranking were selected as shown in Fig. 6. This study modified all the criteria of Chung and Lee (2009a). Fourteen criteria were selected including components of water quantity and quality. As shown in Sect. 3.4, since driving force and pressure components should include the socioeconomic factors and anthropogenic activities, population (D1) and population density (D2) were selected for driving force and urban area ratio $(\mathrm{P} 1)$, groundwater withdrawal $(\mathrm{P} 2)$, slope of watershed (P3), and ratio of covered stream length (P4) were included

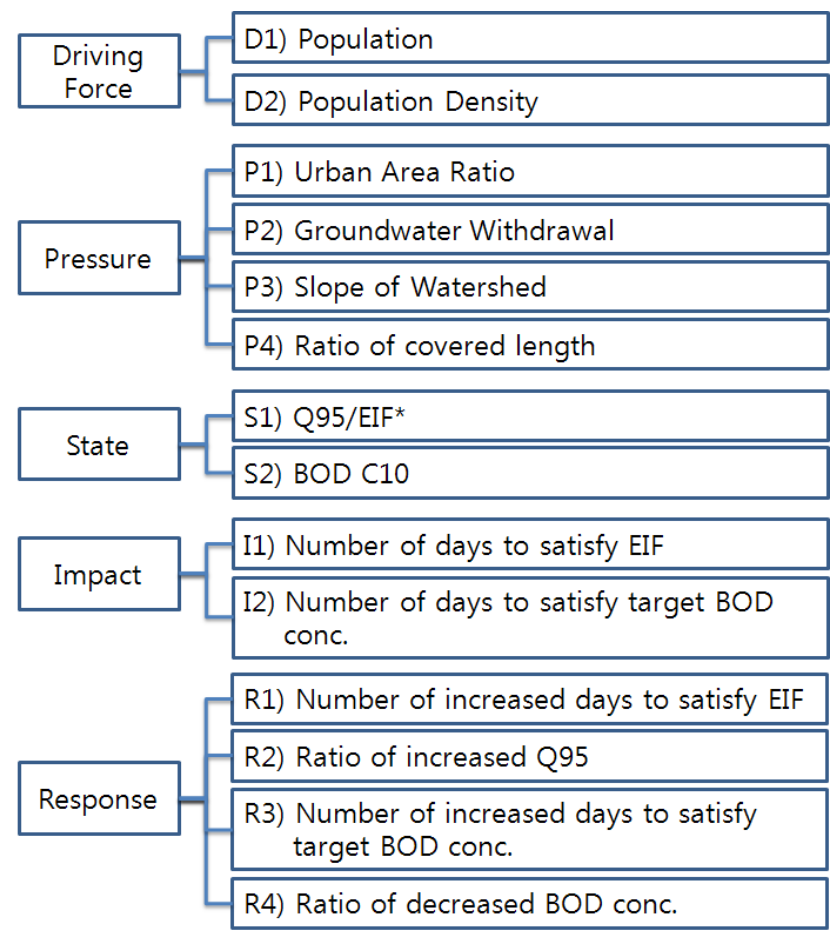

* EIF: Environmental Instream Flow

Fig. 6. Evaluation criteria based on DPSIR framework.

to pressure component. P1 can affect both water quantity and quality directly and P2 and P3 have positive tendency with stream flow quantity during the dry period. P4 can decrease water quality due to intervention of sunlight and inflow of untreated waste water. All standardized values of driving force $\left(c_{1}\right)$, and pressure $\left(c_{2}\right)$ for five alternatives were collected and aggregated from statistical data and GIS analyses, as shown in Fig. 7.

Since state is related to the resulting environmental conditions, 95 percentile value of flow duration curve (Q95) over EIF (S1) and 10-percentile BOD concentration (C10, S2) were selected for water quantity and quality indicators, respectively. In addition, since impact should consider the environmental consequences resulting from state, numbers of days to satisfy EIF (I1) and target BOD concentration (I2) were used. Finally, since response is related to measures taken to improve the environmental state and impact, the changed ratio of four state and impact criteria were proposed. All values of state $\left(c_{3}\right)$, impact $\left(c_{4}\right)$ and response $\left(c_{5}\right)$ were derived by analyzing the simulation results of HSPF, as shown in Table 2 . Since the cost $\left(c_{6}\right)$ must be considered for sustainable management, all costs were estimated, as shown in Fig. 8.

The rankings of five alternatives were analyzed as shown in Table 3. The rankings in Table 3 mean not the fixed values but the most plausible (e.g. the most frequent at all cases). Since the cost is a crucial management component for water 
Table 1. Number of days required satisfying target water quantity and quality.

\begin{tabular}{llllllll}
\hline \multirow{2}{*}{ Alternative } & \multicolumn{3}{c}{ Quantity } & & \multicolumn{3}{c}{ Quality } \\
\cline { 2 - 5 } \cline { 6 - 8 } & P & A1B & A2 & & P & A1B & A2 \\
\hline No Alt & 88.5 & 109.3 & 107.9 & & 170.0 & 176.9 & 175.6 \\
Alt 1 & 97.7 & 119.0 & 118.3 & & 231.6 & 234.0 & 236.9 \\
Rate & $10.5 \%$ & $8.8 \%$ & $9.6 \%$ & & $36.2 \%$ & $32.3 \%$ & $34.9 \%$ \\
No Alt & 109.0 & 132.6 & 130.6 & & 32.3 & 25.4 & 28.3 \\
Alt 2 & 218.8 & 244.4 & 241.6 & & 259.1 & 261.6 & 261.9 \\
Rate & $100.7 \%$ & $84.2 \%$ & $85 \%$ & & $701.3 \%$ & $931.1 \%$ & $825.3 \%$ \\
No Alt & 138.6 & 69.4 & 67.4 & & 46.7 & 28.7 & 28.8 \\
Alt 3 & 278.1 & 122.3 & 122.2 & & 268.8 & 104.9 & 105.2 \\
Rate & $100.7 \%$ & $76.3 \%$ & $81.3 \%$ & & $475.5 \%$ & $265.1 \%$ & $264.9 \%$ \\
Alt 4 & 254.0 & 115.9 & 116.0 & & 153.3 & 65.6 & 63.8 \\
Rate & $83.3 \%$ & $67.1 \%$ & $72.0 \%$ & & $228.2 \%$ & $128.4 \%$ & $121.3 \%$ \\
Alt 5 & 219.0 & 101.2 & 101.0 & & 102.8 & 47.7 & 46.6 \\
Rate & $58.0 \%$ & $45.9 \%$ & $49.8 \%$ & & $120.1 \%$ & $66.1 \%$ & $61.7 \%$ \\
\hline
\end{tabular}

Table 2. Values of state, impact and response.

\begin{tabular}{|c|c|c|c|c|c|c|c|c|c|c|c|c|c|c|c|}
\hline \multirow[t]{2}{*}{ Criteria } & \multicolumn{5}{|c|}{ Present } & \multicolumn{5}{|c|}{ A1B } & \multicolumn{5}{|c|}{ A2 } \\
\hline & Alt 1 & Alt 2 & Alt 3 & Alt 4 & Alt 5 & Alt 1 & Alt 2 & Alt 3 & Alt 4 & Alt 5 & Alt 1 & Alt 2 & Alt 3 & Alt 4 & Alt 5 \\
\hline S1 & 0.35 & 0.41 & 0.36 & 0.36 & 0.36 & 0.37 & 0.43 & 0.40 & 0.40 & 0.40 & 0.35 & 0.44 & 0.43 & 0.43 & 0.43 \\
\hline $\mathrm{S} 2$ & 8.52 & 10.75 & 23.17 & 23.17 & 23.17 & 8.90 & 10.58 & 22.62 & 22.62 & 22.62 & 8.87 & 10.34 & 21.08 & 21.08 & 21.08 \\
\hline I1 & 93.4 & 135.3 & 138.6 & 138.6 & 138.6 & 114.4 & 159.0 & 69.4 & 69.4 & 69.4 & 105.4 & 157.5 & 67.4 & 67.4 & 67.4 \\
\hline I2 & 189.7 & 160.2 & 46.7 & 46.7 & 46.7 & 196.3 & 147.3 & 28.7 & 28.7 & 28.7 & 195.5 & 146.2 & 28.8 & 28.8 & 28.8 \\
\hline $\mathrm{R} 1$ & 11.2 & 67.6 & 100.7 & 83.3 & 58.0 & 9.9 & 60.9 & 76.3 & 67.1 & 45.9 & 18.7 & 60.4 & 81.3 & 72.0 & 49.8 \\
\hline $\mathrm{R} 2$ & 36.4 & 265.8 & 339.9 & 198.3 & 139.7 & 35.2 & 253.7 & 303.2 & 177.1 & 125.1 & 44.2 & 245.1 & 293.6 & 171.4 & 120.4 \\
\hline R3 & 30.3 & 79.4 & 475.5 & 228.2 & 120.1 & 25.7 & 95.9 & 265.1 & 128.4 & 66.1 & 29.0 & 98.1 & 264.9 & 121.3 & 61.7 \\
\hline $\mathrm{R} 4$ & 7.7 & 26.3 & 45.6 & 40.0 & 36.6 & 5.8 & 24.1 & 39.3 & 34.2 & 31.1 & 4.1 & 23.2 & 34.1 & 29.0 & 25.7 \\
\hline
\end{tabular}

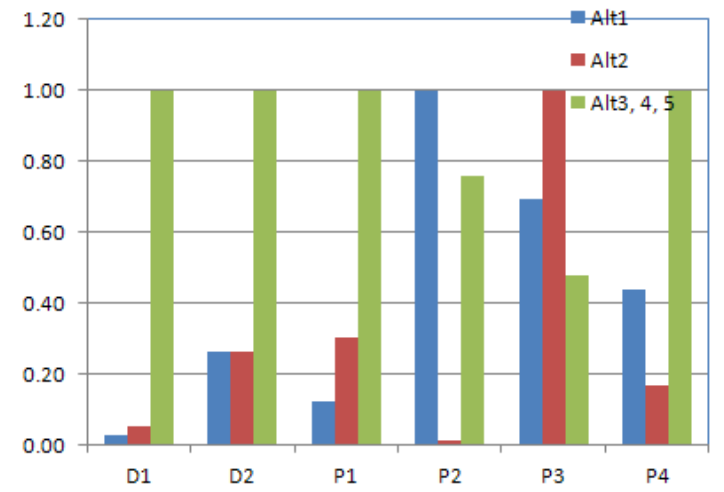

Fig. 7. Standardized values of driving force and pressure.

resources, two scenarios with and without cost were compared. In addition, since the weighting values of all criteria can be assumed differently by every decision maker, this study used some weighting scenarios agreed by five experts. From the discussion, six sets of weighting values were derived as follows:
- WSc 1: (Without cost) All random values

- WSc 2: (Without cost) Response $>$ Impact $>$ State $>$ Pressure $>$ Driving force

- WSc 3: (Without cost) Driving force $=$ Pressure $=0$, State $=0.1$, Impact $=0.3$, and Response $=0.6$

- WSc 4: (With cost) all random values

- WSc 5: (With cost $)$ Cost $=$ Response $>$ Impact $>$ State $=$ Cost $>$ Pressure $>$ Driving force

- WSc 6: (With cost) Driving force $=$ Pressure $=0.05$, State $=0.1$ Impact $=0.15$, Response $=0.25$, and Cost $=0.4$

Five experts working for water resources/watershed planning agreed that WSc 6 is the most reasonable and universal scenario.

As a result, the cost component changed the ranking, largely. With cost, Alts 2 and 5 showed high prioritization, but Alt 3 showed the opposite results. WScs 1, 2, and 3 
Table 3. Prioritization of five alternatives.

\begin{tabular}{|c|c|c|c|c|c|c|c|}
\hline \multicolumn{2}{|c|}{ Scenario } & \multirow{2}{*}{$\begin{array}{l}\text { Weights } \\
\text { Random number; AVF }\end{array}$} & \multirow{2}{*}{$\frac{\text { Alt } 1}{5}$} & \multirow{2}{*}{$\frac{\text { Alt } 2}{4}$} & \multirow{2}{*}{$\frac{\text { Alt } 3}{1}$} & \multirow{2}{*}{$\frac{\text { Alt } 4}{2}$} & \multirow{2}{*}{$\frac{\text { Alt } 5}{3}$} \\
\hline Without Cost & WSc1 & & & & & & \\
\hline & WSc2 & $R>I>S>P>D ;$ AVF & 5 & 4 & 1 & 2 & 3 \\
\hline & WSc3 & $D=P=0, S=0.1, I=0.3, R=0.6 ; \mathrm{AVF}$ & 5 & 4 & 1 & 2 & 3 \\
\hline \multirow[t]{4}{*}{ With } & WSc4 & Random number; AVF & 3 & 2 & 4 & 5 & 1 \\
\hline & WSc5 & $R>I>S>P>D ;$ AVF & 3 & 2 & 4 & 5 & 1 \\
\hline & WSc6 & $D: P: S: I: R: C=0.05: 0.05: 0.1: 0.15: 0.25: 0.4 ; \mathrm{AVF}$ & 4 & 2 & 3 & 5 & 1 \\
\hline & WSc6 & $D: P: S: I: R: C=0.05: 0.05: 0.1: 0.15: 0.25: 0.4 ;$ ELECTRE II & 3 & N/A & 3 & 2 & 1 \\
\hline
\end{tabular}

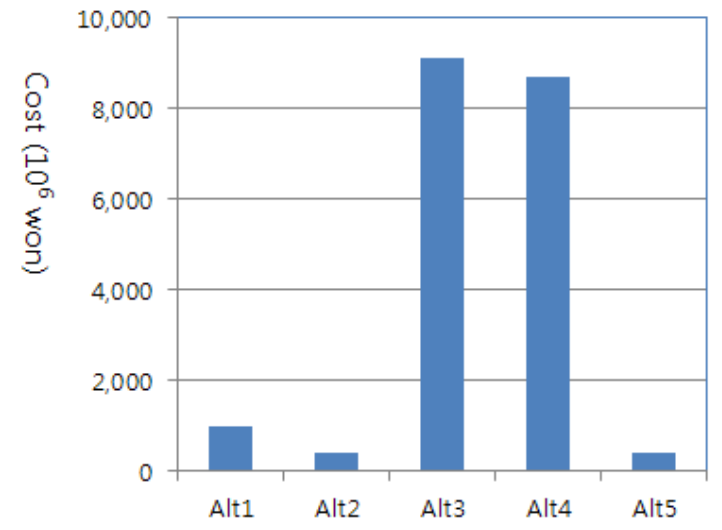

Fig. 8. Cost of all alternatives.

showed the same result. That is, weighting values have no impacts on prioritization of these five alternatives if cost is not considered.

For the consideration of the uncertainty of MCDM techniques, ELECTRE II was added to this decision making problem, as shown in Table 3. Since ELECTRE II showed no different result except WSc 6, only the result of WSc 6 was presented. When ELECTRE II is used, Alt 4 showed a totally different prioritization because of high environmental efficiency. For the final decision, two MCDM results must be considered.

As shown in Sects. 3.5 and 3.6, ELECTRE II and AVF prioritize all alternatives with totally different algorithms. We, therefore, cannot select one method to be more trustful. If you want to determine all ranking with comparatively exact weighting values, AVF will be more convenient. Otherwise, ELECTRE II which can show the outranking priorities will be more effective.

\subsection{Sensitivity analyses to six criteria}

If the base scenario is assumed to be WSc6 with AVF, the relation $P_{5}>P_{2}>P_{3}>P_{1}>P_{4}$ holds, and as a result, the most preferred alternative is $A_{5}$. It can be observed now that according to the weights of the six criteria, criterion cost $\left(c_{6}\right)$

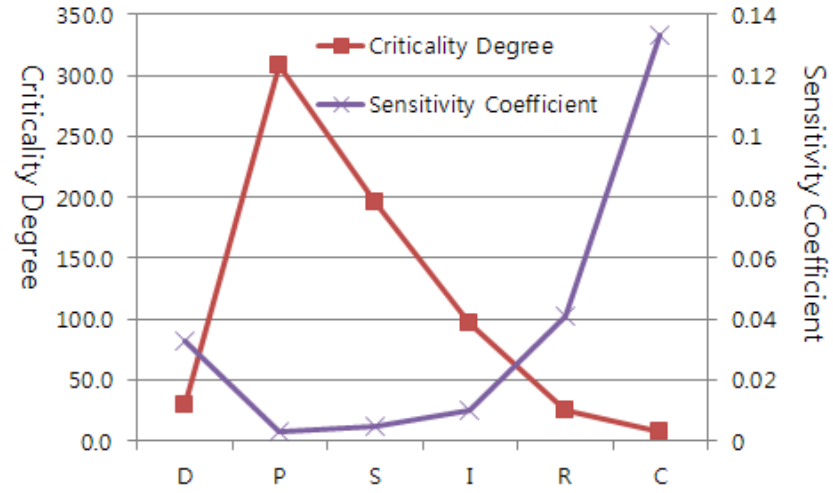

Fig. 9. Criticality degrees $D_{k}^{\prime}$ and sensitivity coefficients $\operatorname{sens}\left(c_{k}\right)$ of the six criteria.

appears to be the most important one. Using Eq. (8), all possible values $\delta_{k, i, j}$ for reversing the current ranks are calculated as shown in Table 4. The minimum change $\delta_{6,1,4}$ is needed to alter the current weight $w_{6}$ in order that the current ranking of the two alternatives $A_{1}$ and $A_{4}$ will be reversed.

Using Eq. (5), all possible weighting values $w_{k}$ for reversing the current ranking were calculated as shown in Table 5. It can be observed that the negative changes in Table 4 indicate increases of weighting values, while positive changes indicate decreases. The highlighted numbers in both tables indicate the minimum critical changes.

The PT critical criterion can be found by looking for the smallest relative value of all rows which are related to alternative $A_{5}$ (i.e. the best alternative) in Fig. 9. The smallest such percentage (i.e. $13.0 \%$ ) corresponds to criterion $c_{6}$ when the pair of alternatives $A_{3}$ and $A_{5}$ is considered. For criterion $c_{6}$ a reduction of its current weight by $68.3 \%$ will make $A_{3}$ the most preferred alternative, and $A_{5}$ will not be the best alternative any more.

The PA critical criterion can be found by looking for the smallest relative $\delta_{k, i, j}^{l}$ value in the entire Fig. 9. Such smallest value is $\delta_{6,1,4}^{l}=7.5 \%$, and it corresponds to criterion $c_{6}$ again. Therefore, the PA critical criterion is $c_{6}$. Finally, as Triantaphyllou (2000) mentioned, it is a coincidence that 
Table 4. All possible $\delta_{k, i, j}$ values (absolute change in criteria weights).

\begin{tabular}{|c|c|c|c|c|c|c|c|}
\hline \multicolumn{2}{|c|}{ Pair of alternatives } & \multicolumn{6}{|c|}{ Criterion } \\
\hline & & Driving force & Pressure & State & Impact & Response & Cost \\
\hline A1 & $\mathrm{A} 2$ & $\mathrm{~N} / \mathrm{F}^{*}$ & -0.747 & $\mathrm{~N} / \mathrm{F}^{*}$ & $\mathrm{~N} / \mathrm{F}^{*}$ & $\mathrm{~N} / \mathrm{F}^{*}$ & $\mathrm{~N} / \mathrm{F}^{*}$ \\
\hline A1 & A3 & 0.035 & $\mathrm{~N} / \mathrm{F}^{*}$ & $\mathrm{~N} / \mathrm{F}^{*}$ & 0.053 & 0.035 & -0.034 \\
\hline A1 & A4 & -0.030 & -0.104 & -0.095 & -0.045 & -0.044 & 0.030 \\
\hline A1 & A5 & $\mathrm{N} / \mathrm{F}^{*}$ & $\mathrm{~N} / \mathrm{F}^{*}$ & $\mathrm{~N} / \mathrm{F}^{*}$ & $\mathrm{~N} / \mathrm{F}^{*}$ & $\mathrm{~N} / \mathrm{F}^{*}$ & $\mathrm{~N} / \mathrm{F}^{*}$ \\
\hline $\mathrm{A} 2$ & A3 & -0.135 & -0.261 & -0.380 & -0.196 & -0.331 & 0.120 \\
\hline $\mathrm{A} 2$ & $\mathrm{~A} 4$ & -0.202 & -0.388 & -0.565 & -0.291 & $\mathrm{~N} / \mathrm{F}^{*}$ & 0.187 \\
\hline $\mathrm{A} 2$ & A5 & $\mathrm{N} / \mathrm{F}^{*}$ & $\mathrm{~N} / \mathrm{F}^{*}$ & $\mathrm{~N} / \mathrm{F}^{*}$ & $\mathrm{~N} / \mathrm{F}^{*}$ & $\mathrm{~N} / \mathrm{F}^{*}$ & $\mathrm{~N} / \mathrm{F}^{*}$ \\
\hline A3 & A4 & $\mathrm{N} / \mathrm{F}^{*}$ & $\mathrm{~N} / \mathrm{F}^{*}$ & $\mathrm{~N} / \mathrm{F}^{*}$ & $\mathrm{~N} / \mathrm{F}^{*}$ & 0.189 & $\mathrm{~N} / \mathrm{F}$ \\
\hline A3 & A5 & $\mathrm{N} / \mathrm{F}^{*}$ & $\mathrm{~N} / \mathrm{F}^{*}$ & $\mathrm{~N} / \mathrm{F}^{*}$ & $\mathrm{~N} / \mathrm{F}^{*}$ & -0.536 & 0.273 \\
\hline A4 & A5 & $\mathrm{N} / \mathrm{F}^{*}$ & $\mathrm{~N} / \mathrm{F}^{*}$ & $\mathrm{~N} / \mathrm{F}^{*}$ & $\mathrm{~N} / \mathrm{F}^{*}$ & $\mathrm{~N} / \mathrm{F}^{*}$ & 0.348 \\
\hline \multicolumn{2}{|c|}{ Number of feasible $\delta$ values } & 4 & 4 & 3 & 4 & 5 & 6 \\
\hline
\end{tabular}

${ }^{*} \mathrm{~N} / \mathrm{F}$ stands for Non-Feasible. That is, the corresponding value $\delta_{k, i, j}$ does not satisfy condition Eq. (10).

both definitions of the most critical criterion indicate the same criterion in this application.

The criticality degrees and sensitivity coefficients of the six criteria were calculated by using Eqs. (6) and (7) as shown in Table 6. As a result, the most sensitive decision criterion is $c_{6}$, followed by the criteria $c_{5}, c_{1}, c_{4}, c_{3}$ and $c_{2}$ in that order. Therefore, the ranking trajectories of five alternatives to criterion $c_{6}$ were derived as shown in Fig. 10. If $c_{6}>0.127, A_{5}$ is the most preferred. Since it is definitely certain that the cost component weighting value is over 0.127 , $A_{5}$ will be the most preferred alternative in this application. From Table 6 and Fig. 10, it can be seen that $A_{5}$ dominates over $A_{1}$ and $A_{2}$. That is, it is impossible to make alternatives $A_{1}$ and $A_{2}$ more preferred than alternative $A_{5}$ by changing the weights of the criteria.

\section{Conclusions}

Numerous studies have analyzed management plans by means of monitoring and hydrologic modelling, but few considered the impacts of both climate change and urbanization. This study presents the analysis results of five alternatives for integrated watershed management under urbanization and climate change scenarios. The climate change scenarios were obtained by using the SDSM model, and the urbanization scenarios by using the existing urban planning. The alternatives for the Anyangcheon watershed consist of reusing WWTP effluent, redeveloping the existing reservoir, construction of a small WWTP and use of groundwater collected by subway stations. The flow and BOD concentration duration curves were derived using the HSPF model.

Therefore, this study analyzed the differences of simulated results between with and without climate change impacts. In these analyses, it is assumed that land use change will occur with climate change for the reality. So, the climate change

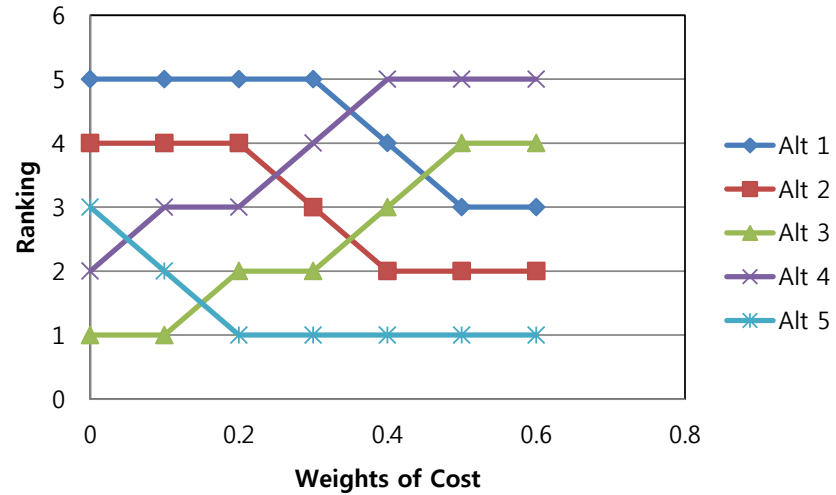

Fig. 10. Ranking trajectories of all alternatives to weights of cost.

scenarios were combined into the planned land use projections. This study compared hydrologic cycles of the present climate and land use conditions with those of the forecasted climate change and planned land use change conditions.

The results of this study showed that the low flows (Q95) and BOD concentration (C10) were very sensitive to the alternatives. Although urbanization distorts the hydrological cycle, effective alternatives can reduce its damage. The climate change reduced the effect of the alternatives on low flow and water quality, while urbanization increased the effectiveness in general. Also climate change affected the effect of the alternatives on water quality more than on water quantity, but urbanization caused the effect on low flow to increase. The impacts of A2 were greater than those of A1B. The numbers of days required to satisfy the target instream flow and BOD concentration were also sensitive to urbanization. In addition, the alternative having large improvement on the hydrological cycle showed a larger decrease in the effectiveness of the alternatives because of the climate change and the urbanization. 
Table 5. All possible weighting values $w_{k}$ (absolute change in criteria weights).

\begin{tabular}{|c|c|c|c|c|c|c|c|}
\hline \multicolumn{2}{|c|}{ Pair of alternatives } & \multicolumn{6}{|c|}{ Criterion } \\
\hline & & Driving force & Pressure & State & Impact & Response & Cost \\
\hline A1 & $\mathrm{A} 2$ & $\mathrm{~N} / \mathrm{F}^{*}$ & 0.797 & $\mathrm{~N} / \mathrm{F}^{*}$ & $\mathrm{~N} / \mathrm{F}^{*}$ & $\mathrm{~N} / \mathrm{F}^{*}$ & $\mathrm{~N} / \mathrm{F}^{*}$ \\
\hline A1 & A3 & 0.015 & $\mathrm{~N} / \mathrm{F}^{*}$ & $\mathrm{~N} / \mathrm{F}^{*}$ & 0.097 & 0.215 & 0.434 \\
\hline A1 & A4 & 0.080 & 0.154 & 0.195 & 0.195 & 0.294 & 0.370 \\
\hline A1 & A5 & $\mathrm{N} / \mathrm{F}^{*}$ & $\mathrm{~N} / \mathrm{F}^{*}$ & $\mathrm{~N} / \mathrm{F}^{*}$ & $\mathrm{~N} / \mathrm{F}^{*}$ & $\mathrm{~N} / \mathrm{F}^{*}$ & $\mathrm{~N} / \mathrm{F}^{*}$ \\
\hline A2 & A3 & 0.185 & 0.311 & 0.480 & 0.346 & 0.581 & 0.280 \\
\hline $\mathrm{A} 2$ & A4 & 0.252 & 0.438 & 0.665 & 0.441 & $\mathrm{~N} / \mathrm{F}^{*}$ & 0.213 \\
\hline $\mathrm{A} 2$ & A5 & $\mathrm{N} / \mathrm{F}^{*}$ & $\mathrm{~N} / \mathrm{F}^{*}$ & $\mathrm{~N} / \mathrm{F}^{*}$ & $\mathrm{~N} / \mathrm{F}^{*}$ & $\mathrm{~N} / \mathrm{F}^{*}$ & $\mathrm{~N} / \mathrm{F}^{*}$ \\
\hline A3 & A4 & $\mathrm{N} / \mathrm{F}^{*}$ & $\mathrm{~N} / \mathrm{F}^{*}$ & $\mathrm{~N} / \mathrm{F}^{*}$ & $\mathrm{~N} / \mathrm{F}^{*}$ & 0.061 & $\mathrm{~N} / \mathrm{F}^{*}$ \\
\hline A3 & A5 & $\mathrm{N} / \mathrm{F}^{*}$ & $\mathrm{~N} / \mathrm{F}^{*}$ & $\mathrm{~N} / \mathrm{F}^{*}$ & $\mathrm{~N} / \mathrm{F}^{*}$ & 0.786 & 0.127 \\
\hline A4 & A5 & $\mathrm{N} / \mathrm{F}^{*}$ & $\mathrm{~N} / \mathrm{F}^{*}$ & $\mathrm{~N} / \mathrm{F}^{*}$ & $\mathrm{~N} / \mathrm{F}^{*}$ & $\mathrm{~N} / \mathrm{F}^{*}$ & 0.052 \\
\hline
\end{tabular}

${ }^{*} \mathrm{~N} / \mathrm{F}$ stands for Non-Feasible. That is, the corresponding value $\delta_{k, i, j}$ does not satisfy condition Eq. (10).

Table 6. All possible $\delta_{k, i, j}^{l}$ values (percent change in criteria weights).

\begin{tabular}{|c|c|c|c|c|c|c|c|}
\hline \multicolumn{2}{|c|}{ Pair of alternatives } & \multicolumn{6}{|c|}{ Criterion } \\
\hline & & Driving force & Pressure & State & Impact & Response & Cost \\
\hline A1 & A2 & $\mathrm{N} / \mathrm{F}^{*}$ & -1493.3 & $\mathrm{~N} / \mathrm{F}^{*}$ & $\mathrm{~N} / \mathrm{F}^{*}$ & $\mathrm{~N} / \mathrm{F}^{*}$ & $\mathrm{~N} / \mathrm{F}^{*}$ \\
\hline A1 & A3 & 71.0 & 248.3 & 113.1 & 53.4 & 13.8 & 108.5 \\
\hline A1 & A4 & -59.6 & -208.7 & -95.1 & -44.9 & -17.5 & 92.5 \\
\hline $\mathrm{A} 1$ & A5 & $\mathrm{N} / \mathrm{F}^{*}$ & $\mathrm{~N} / \mathrm{F}^{*}$ & $\mathrm{~N} / \mathrm{F}^{*}$ & $\mathrm{~N} / \mathrm{F}^{*}$ & $\mathrm{~N} / \mathrm{F}^{*}$ & $\mathrm{~N} / \mathrm{F}^{*}$ \\
\hline $\mathrm{A} 2$ & A3 & -271.0 & -521.6 & -379.6 & -195.7 & -132.3 & 70.1 \\
\hline $\mathrm{A} 2$ & $\mathrm{~A} 4$ & -403.4 & -776.6 & -565.2 & -291.4 & $\mathrm{~N} / \mathrm{F}^{*}$ & 53.3 \\
\hline $\mathrm{A} 2$ & A5 & $\mathrm{N} / \mathrm{F}^{*}$ & $\mathrm{~N} / \mathrm{F}^{*}$ & $\mathrm{~N} / \mathrm{F}^{*}$ & $\mathrm{~N} / \mathrm{F}^{*}$ & $\mathrm{~N} / \mathrm{F}^{*}$ & $\mathrm{~N} / \mathrm{F}^{*}$ \\
\hline A3 & A4 & $\mathrm{N} / \mathrm{F}^{*}$ & $\mathrm{~N} / \mathrm{F}^{*}$ & $\mathrm{~N} / \mathrm{F}^{*}$ & $\mathrm{~N} / \mathrm{F}^{*}$ & 75.6 & $\mathrm{~N} / \mathrm{F}^{*}$ \\
\hline A3 & A5 & $\mathrm{N} / \mathrm{F}^{*}$ & $\mathrm{~N} / \mathrm{F}^{*}$ & $\mathrm{~N} / \mathrm{F}^{*}$ & $\mathrm{~N} / \mathrm{F}^{*}$ & -214.2 & 31.8 \\
\hline A4 & A5 & $\mathrm{N} / \mathrm{F}^{*}$ & $\mathrm{~N} / \mathrm{F}^{*}$ & $\mathrm{~N} / \mathrm{F}^{*}$ & $\mathrm{~N} / \mathrm{F}^{*}$ & $\mathrm{~N} / \mathrm{F}^{*}$ & 13.1 \\
\hline
\end{tabular}

${ }^{*} \mathrm{~N} / \mathrm{F}$ stands for Non-Feasible. That is, the corresponding value $\delta_{k, i, j}$ does not satisfy condition Eq. (10).

Finally, prioritization of water management options must include climate change and urbanization impacts since the anticipated effectiveness of all alternatives for watershed management, which was estimated at the design process, is more likely to be changed if climate change and urbanization are not considered. All the criteria were selected from DPSIR framework. Moreover, since the cost is a crucial management component for water resources, two scenarios of with and without cost were compared.

An analysis of social and economic components, and uncertainty of weighting values and MCDM techniques for decision making revealed that the most sensitive decision criterion is cost, followed by the criteria response, driving force, impact, state and pressure in that order. Since it is definitely certain that the importance of cost component is over 0.127 , Alt 5 was found to be the most preferred alternative in this application. These results led us to conclude that climate change and urbanization should be considered simultaneously in water resource management and planning. Lastly, the cost must be included in the real design along with the sensitivity analyses of weighting values of all criteria.

Since this study focused on the development of decision making procedure considering climate change and urbanization, just one GCM result was used. However, it is widely known that especially the precipitation outputs of GCM are highly uncertain, i.e. different climate models usually produce different precipitation trends. Also, there is the uncertainty connected to the intra-annual distribution of precipitation which can be quite different among several climate models. Additionally, recent studies have shown that also the downscaling method can contribute significantly to the uncertainty envelope. In the future, therefore, it is strongly recommended that various climate change models be included to minimize the uncertainty due to climate models. 
Acknowledgements. This study was supported in part by the Basic Science Research Program of the National Research Foundation of Korea (NRF) funded by the Ministry of Education, Science and Technology (2010-0010609) (50\%). It was also supported in part by the Basic Science Research Program of the National Research Foundation of Korea (NRF) funded by the Ministry of Education, Science and Technology (2011-0013598) (50\%).

Edited by: A. Guadagnini

\section{References}

Al-Juaidi, A. E., Kaluarachchi, J. J., and Kim, U.: Multi-criteria decision analysis of treated waste water use for agriculture in water deficit regions, J. Am. Water Resour. Assoc., 46, 395-411, 2010.

Bae, D.-H., Jung, I.-W., and Chang, H.: Regional impacts of climate change on water resources in Korea by using a high resolution scenario, Clim. Res., 35, 213-226, 2007.

Bicknell, B. R., Imhoff, J. C., Kittle Jr., J. L., Jobes, T. H., and Donigian, A. S.: Hydrologic Simulation Program-Fortran (HSPF) User's Manual for Version 12, US Environmental Protection Agency, National Exposure Research Laboratory, Athens, GA, 2001.

Caldeira, K., Jain, A. K., and Hoddert, M. I.: Climate sensitivity uncertainty and the need for energy without $\mathrm{CO}_{2}$ emission, Science, 299, 2052-2054, 2003.

Carter, T. R., La Rovere, E. L., Jones, R. N., Leemas, R., Mearns, L. O., Nakicenovic, N., Pittock, A. B., Semenov, S. M., and Skea, J.: Developing and Applying Scenarios, in: Climate Change 2001: Impacts, Adaptation, and Vulnerability, edited by: IPCC, Cambridge University Press, Cambridge, 145-190, 2001.

Chen, S. and Hou, Z.: Multicriterion decision making for flood control operations: Theory and applications, J. Am. Water Resour. Assoc., 40, 67-76, 2004.

Chung, E. S. and Lee, K. S.: Prioritization of water management for sustainability using hydrologic simulation model and multicriteria decision making techniques, J. Environ. Manage., 90, 1502-1511, 2009a.

Chung, E. S. and Lee, K. S.: Identification of spatial ranking of hydrological vulnerability using multi-criteria decision making techniques: Case study of Korea, Water Resour. Manage., 23, 2395-2416, 2009b.

Chung, E. S., Hong, W. P., Lee, K. S., and Burian, S.: Integrated Use of a Continuous Simulation Model and Multi-attribute Decision Making for Ranking Urban Watershed Management Alternatives, Water Resour. Manage., 25, 641-659, 2011 a.

Chung, E. S., Kim, K. T., Lee, K. S., and Burian, S.: Incorporating Uncertainty and Objective Load Reduction Allocation into the TMDL Process in Korea, KSCE J. Civil Eng., 15, 1289-1297, $2011 b$.

Chung, E. S., Park, K., and Lee, K. S.: The relative impacts of climate change and urbanization on the hydrological response of a Korean urban watershed, Hydrol. Process., 25, 544-560, 2011c.

Clemen, R. T.: Making Hard Decisions: An Introduction to Decision Analysis, Duxbury Press, Belmont, California, 1997.

European Environment Agency: Environmental Indicators: Typology and Overview, Copenhagen, Denmark, 1999.
Hallegatte, S.: Strategies to adapt to an uncertain climate change, Global Environ. Change, 19, 240-247, 2009.

Hejazi, M. and Moglen, G. E.: The effect of climate and land use change on flow duration in the Maryland Piedmont region, Hydrol. Process., 22, 4710-4722, 2008.

Hobbs, B. F.: Bayesian methods for analyzing climate change and water resource uncertainties, J. Environ. Manage., 49, 53-72, 1997.

Hobbs, B. F., Chao, P. T., and Venkatesh, B. N.: Using decision analysis to include climate change in water resources decision making, Climatic Change, 37, 177-202, 1997.

Huang, G. H., Cohen, S. J., Yin, Y. Y., and Bass, B.: Land resources adaption planning under changing climate - A study for the Mackenzie basin, Resour. Conserv. Recycl., 24, 95-119, 1998.

IPCC: Climate change 2001: The Science Basis, Contribution of Working Group II to the IPCC Third Assessment Report, Cambridge University Press, UK, 2001.

IPCC: Climate Change 2007: The Physical Science Basis, Contribution of Working Group I to the IPCC Fourth Assessment Report, Cambridge University Press, UK, 2007.

Lee, K. S. and Chung, E. S.: Hydrological effects of climate change, groundwater withdrawal, and landuse in the small Korea watershed, Hydrol. Process., 21, 3046-3056, 2007a.

Lee, K. S. and Chung, E. S.: Development of integrated watershed management schemes for intensively urbanized region in Korea, J. Hydro-Environ. Res., 1, 95-109, 2007b.

Lee, K. S., Chung, E. S., and Kim, Y. O.: Integrated watershed management for mitigating streamflow depletion in an urbanized watershed in Korea, Phys. Chem. Earth, 33, 382-394, 2008.

Lempert, R. J. and Schlesinger, M. E.: Robust strategies for abating climate change, Climatic Change, 45, 387-401, 2000.

Lempert, R. J., Schlesinger, M. E., and Bankes, S. C.: When we don't know the costs or the benefits: Adaptive strategies for abating climate change, Climatic Change, 33, 235-274, 1996.

Levy, J. K., Hartmann, J., Li, K. W., An, Y., and Asgary, A.: Multicriteria decision support systems for flood hazard mitigation and emergency response in urban watersheds, J. Am. Water Resour. Assoc., 43, 346-358, 2007.

Meyer, V., Scheuer, S., and Haase, D.: A Multicriteria approach for flood risk mapping exemplified at the Mulde River, Germany, Nat. Hazards, 48, 17-39, 2009.

Pavlikakis, G. E. and Tsihrintzis, V. A.: Integrating humans in ecosystem management using multi-criteria decision making, J. Am. Water Resour. Assoc., 39, 277-288, 2003.

Praskievicz, S. and Chang, H.: A review of hydrologic modeling of basin-scale climate change and urban development impacts, Progr. Phys. Geogr., 33, 650-671, 2009.

Qin, X. S., Huang, G. H., Chakma, A., Nie, X. H., and Li, Q. G.: A MCDM-based expert system for climate-change impact assessment and adaptation planning - A case study for Georgia basin, Canada, Expert Systems with Applications, 34, 2164 2179, 2008.

Risbey, J. S.: Sensitivities of water supply planning decisions to streamflow and climate scenario uncertainties, Water Policy, 1, 321-340, 1998.

Skoulikidis, N. Th.: The environmental state of rivers in the Balkans: A review within the DPSIR framework, Sci. Total Environ., 407, 2501-2516, 2009. 
Smith, J. B.: Setting priorities for adapting to climate change, Global Environ. Change, 7, 251-264, 1997.

Sulis, M., Marrocu, M., and Paniconi, C.: Conjunctive use of a hydrological model and a multicriteria decision support system for a case study on the Caia catchment, Portugal, J. Hydrol. Eng.ASCE, 14, 141-152, 2009.

Triantaphyllou, E.: Multi-Criteria Decision Making Methods: A Comparative Study, Kluwer Academic Publisher, 2000.

Triantaphyllou, E. and Sanchez, A.: A sensitivity analysis approach for some deterministic multi-criteria decision-making methods, Decision Sci., 28, 151-194, 1997.

Van Lenthe, J., Hendrickx, L., Biesiot, W., and Vlek, C: A decisionanalytic approach to the integrated assessment of climate change, Risk Decision Policy, 2, 213-234, 1997.

Wilby, R. L., Dawson, C. W., and Barrow, E. M.: SDSM - A decision support tool for the assessment of regional climate change impacts, Environ. Modell. Softw., 17, 147-159, 2002.
Yin, Y.: Designing an Integrated Approach for Evaluating Adaptation Options to Reduce Climate Change Vulnerability in the Georgia Basin, Climate Change Action Fund, Adaptation Liaison Office, National Resources Canada, Ottawa, Canada, 2001.

Yin, Y. and Cohen, S.: Identifying regional policy concerns associated with global climate change, Global Environ. Change, 4, 245-260, 1994.

Yohe, G.: Uncertainty, Climate Change and the Economic Value of Information - An Economic Methodology for Evaluating the Timing and Relative Efficacy of Alternative Response to Climate Change with Application to Protecting Developed Property from Greenhouse Induced Sea-level Rise, Policy Sci., 24, 245-269, 1996.

Yohe, G., Andronova, N., and Schlesinger, M.: Climate - To hedge or not against an uncertain climate, Science, 306, 416-417, 2004.

Zardari, N. H., Cordery, I., and Sharma, A.: An objective multiattribute analysis approach for allocation of scarce irrigation water resources, J. Am. Water Resour. Assoc., 46, 412-428, 2010. 